\title{
Substituent Effects of Porphyrin on Singlet Oxygen Generation Quantum Yields
}

\author{
Fotis Nifiatis*, Jasmin C. Athas, K. Don Dasitha Gunaratne, Yashuda Gurung, Karissa Mae Monette \\ and Philip Joseph Shivokevich
}

Department of Chemistry, State University of New York at Plattsburgh, Plattsburgh, NY 12901, USA

\begin{abstract}
The singlet oxygen photosensitizing efficiencies of the ortho-, meta-, and para-substituted free-base and zinc (II) tetraarylporphyrins have been investigated on the basis of the heavy atom effect, electronegativity, and spatial orbital overlap. Both the endocyclic and exocyclic heavy atom effects have been exploited to induce various degrees of spin-orbit coupling. The ground state and the lowest singlet excited electronic state of the porphyrins have been studied using optical absorption and fluorescence emission spectroscopic techniques. The experimental data suggest that implementation of the halogen substituent effect to enhance the photosensitizing properties of a chromophore from the excited triplet state should be done cautiously, as it may have negative implications.
\end{abstract}

Keywords: Halogenated porphyrins, heavy atom effect, singlet oxygen generation quantum yield, photodynamic therapy.

\section{INTRODUCTION}

For the last 50 years, the generation and reactivity of singlet oxygen have become the focus of intense laboratory studies due to the associated numerous and diverse implications, which include photodynamic therapy (PDT) of cancer [1], DNA photodamage [2], photoxidation [3], and polymer science [4]. Singlet oxygen can be produced either chemically [5] or photochemically [6], with the latter being the most popular. Once generated, singlet oxygen can decay radiatively or non-radiatively or be quenched by physical or chemical processes.

The combination of visible or near-IR light and a photosensitizer (PS), a non-toxic dye, in the presence of oxygen produces a cytotoxic effect in biological systems [1]. Singlet oxygen has been identified as the cytotoxic species responsible for the cellular apoptosis and necrosis of targeted tissue. These effects occur as a result of the reaction of singlet oxygen with a variety of cellular components, such as amino acids [7], nucleosides [8], and unsaturated lipids [9] to produce cytotoxic effects to subcellular organelles and biomolecules. At the molecular level, the mechanism of activity of the PS involves the absorption of a photon, exciting the PS to the singlet excited state $\left(\mathrm{S}_{1}\right)$, while intersystem crossing (ISC) populates the excited triplet state $\left(T_{1}\right)$ of the PS. Unlike most molecules, molecular oxygen has two singlet states $\left({ }^{1} \mathrm{O}_{2}:{ }^{1} \Delta_{g}\right.$, low energy singlet state and ${ }^{1} \Sigma_{g}^{+}$, high energy singlet state) lying above its triplet ground state $\left({ }^{3} \mathrm{O}_{2}:{ }^{3} \Sigma_{\mathrm{g}}^{-}\right)$[10]. According to the intercombination selection rule, direct optical excitation of molecular oxygen from its ground triplet state to the excited

\footnotetext{
*Address correspondence to this author at the Department of Chemistry, State University of New York at Plattsburgh, Plattsburgh, NY 12901, USA; Tel: +1-518-564.2703; Fax: +1-518-564.3169;

E-mail: Fotis.Nifiatis@Plattsburgh.edu
}

singlet state is spin-forbidden. The photosensitization of singlet oxygen is possible with collisional deactivation of the excited triplet state PS to the ground state triplet oxygen, producing excited singlet oxygen and a ground state PS [11]. For efficient energy transfer, the energy levels of the excited triplet PS and singlet molecular oxygen should match. Since the energy of the singlet oxygen is about $0.98 \mathrm{eV}$ [12], the energy difference between the singlet ground and the first triplet excited state of the PS should be equal to or greater than $0.98 \mathrm{eV}$.

Presently, most potential PSs are tetrapyrrole macromolecules. Their low dark toxicity, the ease with which they can be functionalized, and their easily tunable photophysical properties make them an attractive class of compounds for clinical PDT. Potent PSs should possess high singlet oxygen generation quantum yields, a property that is shared among chromophores with long triplet lifetime and high triplet quantum yield. A traditional strategy for increasing the triplet population involves invoking the internal heavy atom effect, in which halogen atoms are substituted onto the porphyrin [13].

Qualitative studies have indicated that halogenated porphyrin-based PSs have enhanced singlet oxygen generation quantum yields [14]. Pineiro et al. [14d] reported that orthofluorinated and ortho-chlorinated porphyrins, chlorines, and bacteriochlorines efficiently sensitize the formation of singlet oxygen. The authors reported that the number and type of halo-substituents at the ortho-position of the meso-phenyl groups significantly improve the singlet oxygen generation quantum yield of the macrocycle. Serra et al. [14b] studied the photodynamic activity of ortho- and para-substituted bromo- and iodo- derivatives of meso-(3-hydroxy)phenylporphyrin. The hydroxyl group on the meso-phenyl substituents increases the affinity of the porphyrin for the carcinogenic cells while the heavy atom effect induced by the bro- 
mine and iodine atoms enhances the ability of the chromophore to generate singlet oxygen. The authors explained the observed increase on the basis of atomic mass and number of halogen atoms attached to the macrocycle. There are numerous other studies that take into consideration the type and number of halo-substituents to show that halogenated porphyrinoids exhibit greater singlet oxygen quantum yields compared to the unsubstituted analogues. However, there have been very few quantitative studies designed to provide direct correlation between the nature and position of the heavy atom substituent and the chromophore's ability to generate singlet oxygen. Bonnett et al. [15] reported that halogenation at the meso, pyrrole, and alkyl carbon atoms of the free-base octaethyl porphyrin $\left(\mathrm{H}_{2} \mathrm{OEP}\right)$ resulted in decreased fluorescence quantum yields and lifetimes, increased phosphorescence quantum yields, and decreased triplet lifetime. The observed effects of halogenation on the photophysical properties of $\mathrm{H}_{2} \mathrm{OEP}$ increase with increasing atomic number for the halo-substituent and depend on the site of halogenation, with the meso-position being the most effective, followed by the $\beta$-pyrrole. The report did not provide an analysis of the effect of halo-substituents on the ability of the chromophores to generate singlet oxygen.

Since the generation of photosensitized singlet oxygen involves energy transfer from the excited triplet state of the PS, consideration should be given to both triplet quantum yields and lifetimes of prospective chromophores. Even though the heavy atom effect may be used to populate the excited triplet state through ISC, a subsequent increase in the otherwise forbidden decay from the triplet to the ground state of the chromophore will shorten the triplet's lifetime and limit energy transfer from the triplet state of the PS to the ground state molecular oxygen.

This report will document and describe the effect of the halogenation of the meso-phenyl groups of the free-base and zinc(II) tetrakisphenylporphyrin derivatives on their ability to generate singlet oxygen with focus on the basis of the heavy atom effect, electronegativity, and spatial orbital overlap. The experimental data have been analyzed in terms of the heavy substituent's atomic number, electronegativity, spatial arrangement, and orbital overlap with the porphyrins $\pi$-system. The data analysis indicates that the propensity for the halogen substituent effect to enhance the photosensitizing properties of a chromophore from the excited triplet state should be viewed with caution, since the opposite outcome is possible as well. For instance, in metalloporphyrins, the strong electronegative character of the halogen atoms seems to reduce the endocyclic internal heavy atom effect induced by the central metal cation. Furthermore, orbital overlap between the porphyrin macrocycle and a halo-substituent at the ortho-position of the phenyl groups seems to significantly increase non-radiative decay from the excited triplet state to the ground state of the chromophore, shortening the lifetime of the excited triplet and decreasing the singlet oxygen quantum yield.

Due to the inherent variability of these types of experiments arising from the specific experimental conditions used, our photophysical measurements on 14 compounds can serve as a self-consistent database necessary to provide guidelines for future development in the field.

\section{EXPERIMENTAL}

\subsection{General}

Ground state UV-Vis absorption spectra were recorded on a Perkin Elmer Lambda 650 spectrophotometer using a $0.1 \mathrm{~nm}$ data interval. Fluorescence emission spectra were recorded on a Perkin-Elmer LS 55B fluorometer at $22{ }^{\circ} \mathrm{C}$, using a $5 \mathrm{~nm}$ bandpath at the excitation and emission legs. Dilute porphyrin solutions, O.D. less than 0.1 , in benzene were used after argon deoxygenation. Fluorescence quantum yields $\left(\Phi_{\mathrm{Fl}}\right)$ were determined on the optically dilute samples using $\mathrm{H}_{2} \mathrm{TPP}\left(\Phi_{\mathrm{Fl}}=0.110\right)$ and $\mathrm{ZnTPP}\left(\Phi_{\mathrm{Fl}}=0.033\right)$ as the reference standards [16]. Phase modulation technique was used to measure fluorescence lifetimes $\left(\tau_{\mathrm{Fl}}\right)$ on a Spex Tau 2 spectroflorimeter with Ludox used as the scatter. Phase and amplitude modulation in the range of $10-200 \mathrm{MHz}$ was used for the free-base porphyrins and $100-300 \mathrm{MHz}$ for the zinc(II) derivatives. Samples deoxygenated with argon and having a porphyrin concentration of $5 \mu \mathrm{M}$ in benzene were excited in the Soret band. Mass spectra were obtained on a micromass ZAB-SEQ instrument.

\subsection{Chemicals}

All solvents and reagents were acquired from SigmaAldrich (U.S.) and purified using standard procedures. Pyrrole used for the synthesis of the porphyrins was distilled at ambient pressure from $\mathrm{CaH}_{2}$. The 9,10-Dimethylanthracence (DMA) was acquired from Sigma-Aldrich (U.S.) and used without further purification. Benzene and toluene used for spectroscopic measurements were distilled over sodium.

\subsection{Porphyrin Synthesis}

Structures and abbreviated nomenclature for compounds used in this study are given in Fig. (1). All porphyrins were synthesized according previously published procedures [17]. The synthesized compounds were characterized by elemental analysis and mass spectroscopy, while their UV-Vis spectra match those previously reported [17]. (Information concerning the characterization can be found in the supporting material.) The fluorescence excitation spectra of all compounds employed in this study agreed well with the corresponding absorption spectra, serving as an additional confirmation of sample purity.

\subsection{Determination of the Singlet Oxygen Generation Quantum yields}

Singlet oxygen generation quantum yields $\left(\Phi_{\Delta}\right)$ were determined photolytically using 9,10-dimethylanthracene (DMA). The photooxidation of DMA, sensitized by the photosensitizer, was carried out in air-saturated toluene and monitored at $401 \mathrm{~nm}$. $\mathrm{H}_{2} \mathrm{TPP}$ in toluene was used as standard $\left(\Phi_{\Delta}=0.63\right)$ [18]. The general procedure is presented below:

A solution of DMA $(100 \mu \mathrm{M})$ and the photosensitizer, with O.D. adjusted at the maximum of the Soret band such that all the photosensitizers absorbed equally, was irradiated in equilibrium with the atmosphere at ambient temperature for an hour. Irradiation was performed using a $100 \mathrm{~W}$ xenon lamp as the light source, and optical filters were used to achieve a spectral window of $400-700 \mathrm{~nm}$. The DMA/PS solution was placed at a distance of $30 \mathrm{~cm}$ from the light source and magnetically stirred during irradiation. 


\section{RESULTS}

\subsection{Ground State Absorption Spectroscopy}

A series of halogenated tetrakisphenylporphyrins and corresponding zinc(II) complexes were synthesized and used to elucidate the effects of changing the halogen attached to the meso-phenyl group on the photophysical and singlet oxygen yields of $\mathrm{H}_{2}$ TPP and ZnTPP. Fig. (1) lists the structures of the 14 porphyrins employed in this study. Molar absorptivity coefficients for bands were estimated from the Beer-Lambert law using solutions with concentrations in the $0.01-10 \mu \mathrm{M}$ range. The experiments show no deviation from the Beer-Lambert law, indicating that the chromophores do not aggregate in this concentration range.

The introduction of halogen atoms into the meso-phenyl group of the $\mathrm{H}_{2}$ TPP and ZnTPP molecules only modestly perturbs the electronic ground state absorption spectra of the macrocycle, whose form is typical of porphyrins as de-

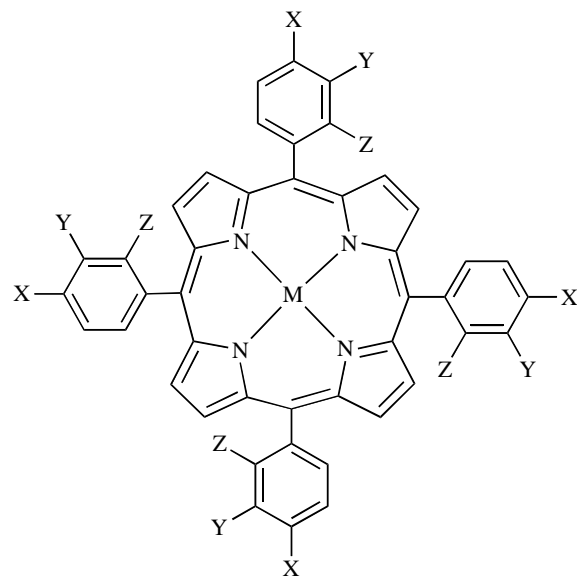

scribed by the four-orbital model [19]. The ground state absorption spectra of the halo-substituted $\mathrm{H}_{2} \mathrm{TPP}$ derivatives, recorded in benzene, contain the Soret band around $419 \mathrm{~nm}$ and four other weaker bands, the $\mathrm{Q}_{\mathrm{y}}(1-0), \mathrm{Q}_{\mathrm{y}}(0-0), \mathrm{Q}_{\mathrm{x}}(1-0)$, and $\mathrm{Q}_{\mathrm{x}}(0-0)$ bands, around $515,549,592$, and $652 \mathrm{~nm}$, respectively. Similarly, the ground state absorption spectra of the halogenated ZnTPP series in benzene is characterized by a strong near-UV Soret band, around $424 \mathrm{~nm}$, and two weaker bands, the $\mathrm{Q}(1-0)$ and $\mathrm{Q}(0-0)$, around 550 and 582 $\mathrm{nm}$, respectively. The strong interaction of the zinc(II) $\mathrm{d}$ orbitals with the macrocycle is responsible for the significant red shift observed in the ground state absorption spectra of the $\mathrm{ZnTPP}$ with respect to the free-base porphyrin, $\mathrm{H}_{2} \mathrm{TPP}$. Again, based on the four-orbital model, the highest energy band, Soret, has been assigned to the $\mathrm{S}_{0} \rightarrow \mathrm{S}_{2}$ transition, while the lower energy bands, Q-bands, have been assigned to the $S_{0} \rightarrow S_{1}$ transition. The ground state absorption characteristics of the free-base porphyrins and those of zinc(II) metalloporphyrins are listed in Tables $\mathbf{1}$ and $\mathbf{2}$, respectively.

\begin{tabular}{|c|c|c|c|c|}
\hline Porphyrin & $\mathbf{M}$ & $\mathbf{X}$ & $\mathbf{Y}$ & $\mathbf{Z}$ \\
\hline $\mathrm{H}_{2}$ TPP & \multirow{7}{*}{$2 \mathbf{H}^{+}$} & $\mathbf{H}$ & \multirow{5}{*}{$\mathbf{H}$} & \multirow{5}{*}{$\mathbf{H}$} \\
\hline $\mathbf{H}_{2} \mathrm{~T}$ (p-F-P)P & & $\mathbf{F}$ & & \\
\hline $\mathrm{H}_{2} \mathrm{~T}(\mathrm{p}-\mathrm{Cl}-\mathrm{P}) \mathbf{P}$ & & $\mathbf{C l}$ & & \\
\hline $\mathrm{H}_{2} \mathrm{~T}(\mathrm{p}-\mathrm{Br}-\mathrm{P}) \mathrm{P}$ & & $\mathbf{B r}$ & & \\
\hline $\mathrm{H}_{2} \mathrm{~T}(\mathrm{p}$-I-P)P & & I & & \\
\hline $\mathrm{H}_{2} \mathrm{~T}(\mathrm{~m}-\mathrm{Cl}-\mathrm{P}) \mathrm{P}$ & & $\mathbf{H}$ & $\mathrm{Cl}$ & $\mathbf{H}$ \\
\hline H & & $\mathbf{H}$ & $\mathbf{H}$ & $\mathrm{Cl}$ \\
\hline ZnTPP & \multirow{7}{*}{$\mathrm{Zn}^{2+}$} & $\mathbf{H}$ & \multirow{5}{*}{$\mathbf{H}$} & \multirow{5}{*}{$\mathbf{H}$} \\
\hline ZnT(p-F-P)P & & $\mathbf{F}$ & & \\
\hline ZnT(p-Cl-P)P & & $\mathrm{Cl}$ & & \\
\hline ZnT(p-Br-P)P & & $\mathrm{Br}$ & & \\
\hline ZnT(p-I-P)P & & I & & \\
\hline ZnT(m-Cl-P)P & & $\mathbf{H}$ & $\mathrm{Cl}$ & $\mathbf{H}$ \\
\hline ZnT(o-Cl-P)P & & $\mathbf{H}$ & $\mathbf{H}$ & $\mathrm{Cl}$ \\
\hline
\end{tabular}

Fig. (1). Structure of porphyrin and metalloporphyrin based photosensitizers.

Table 1. Ground State Absorption Data of Free-Base Porphyrins in De-Aerated Benzene Solutions

\begin{tabular}{|c|c|c|c|c|c|c|}
\hline \multirow{2}{*}{ Porphyrin } & \multicolumn{5}{|c|}{$\lambda_{\max }(\mathbf{n m})\left[\varepsilon\left(\mathbf{x} 10^{-3} \mathbf{M}^{-1} \mathbf{c m}^{-1}\right)\right]$} & \multirow{2}{*}{$\mathbf{Q}(\mathbf{0 - 0}) /\left(\mathbf{Q}(\mathbf{1 - 0})^{2}\right.$} \\
\hline & Soret or $\mathbf{B}(0-0)$ & Qy(1-0) & Qy (0-0) & Qx(1-0) & Qx (0-0) & \\
\hline $\mathrm{H}_{2} \mathrm{TPP}$ & $\begin{array}{c}419.2 \\
{[443.0]}\end{array}$ & $\begin{array}{l}514.9 \\
{[18.2]}\end{array}$ & $\begin{array}{c}548.9 \\
{[8.5]}\end{array}$ & $\begin{array}{l}592.9 \\
{[4.6]}\end{array}$ & $\begin{array}{c}650.4 \\
{[5.5]}\end{array}$ & 0.49 \\
\hline $\mathbf{H}_{2} \mathrm{~T}(\mathrm{p}-\mathrm{F}-\mathrm{P}) \mathbf{P}$ & $\begin{array}{c}419.3 \\
{[440.0]}\end{array}$ & $\begin{array}{c}514.6 \\
{[17.7]} \\
\end{array}$ & $\begin{array}{l}549.1 \\
{[8.4]} \\
\end{array}$ & $\begin{array}{l}592.0 \\
{[4.6]} \\
\end{array}$ & $\begin{array}{c}652.0 \\
{[5.4]} \\
\end{array}$ & 0.49 \\
\hline $\mathbf{H}_{2} \mathbf{T}(\mathbf{p}-\mathrm{Cl}-\mathrm{P}) \mathbf{P}$ & $\begin{array}{c}420.4 \\
{[434.3]}\end{array}$ & $\begin{array}{l}515.1 \\
{[15.3]}\end{array}$ & $\begin{array}{c}550.2 \\
{[6.7]} \\
\end{array}$ & $\begin{array}{c}592.8 \\
{[4.5]} \\
\end{array}$ & $\begin{array}{l}649.2 \\
{[3.9]} \\
\end{array}$ & 0.48 \\
\hline $\mathrm{H}_{2} \mathrm{~T}(\mathrm{p}-\mathrm{Br}-\mathrm{P}) \mathrm{P}$ & $\begin{array}{c}421.0 \\
{[425.3]}\end{array}$ & $\begin{array}{l}515.6 \\
{[15.8]} \\
\end{array}$ & $\begin{array}{l}550.0 \\
{[6.0]} \\
\end{array}$ & $\begin{array}{l}592.2 \\
{[6.0]} \\
\end{array}$ & $\begin{array}{l}651.6 \\
{[2.7]} \\
\end{array}$ & 0.47 \\
\hline $\mathbf{H}_{2} \mathrm{~T}(\mathrm{p}-\mathrm{I}-\mathrm{P}) \mathbf{P}$ & $\begin{array}{c}422.3 \\
{[429.1]}\end{array}$ & $\begin{array}{l}516.8 \\
{[15.4]}\end{array}$ & $\begin{array}{c}550.8 \\
{[6.0]}\end{array}$ & $\begin{array}{c}591.1 \\
{[5.0]}\end{array}$ & $\begin{array}{c}654.0 \\
{[2.1]}\end{array}$ & 0.44 \\
\hline $\mathbf{H}_{2} \mathbf{T}(\mathbf{p}-\mathrm{Cl}-\mathrm{P}) \mathbf{P}$ & $\begin{array}{c}420.4 \\
{[434.3]}\end{array}$ & $\begin{array}{l}515.1 \\
{[15.3]} \\
\end{array}$ & $\begin{array}{c}550.2 \\
{[6.7]} \\
\end{array}$ & $\begin{array}{c}592.8 \\
{[4.5]} \\
\end{array}$ & $\begin{array}{l}649.2 \\
{[3.9]} \\
\end{array}$ & 0.48 \\
\hline $\mathbf{H}_{2} \mathbf{T}(\mathbf{m}-\mathrm{Cl}-\mathrm{P}) \mathbf{P}$ & $\begin{array}{c}420.1 \\
{[399.6]}\end{array}$ & $\begin{array}{l}514.2 \\
{[16.8]}\end{array}$ & $\begin{array}{l}549.2 \\
{[6.5]}\end{array}$ & $\begin{array}{l}592.0 \\
{[4.5]}\end{array}$ & $\begin{array}{c}652.3 \\
{[6.3]}\end{array}$ & 0.47 \\
\hline $\mathbf{H}_{2} \mathbf{T}(\mathbf{o}-\mathrm{Cl}-\mathrm{P}) \mathbf{P}$ & $\begin{array}{c}418.7 \\
{[413.3]}\end{array}$ & $\begin{array}{c}512.1 \\
{[17.3]}\end{array}$ & $\begin{array}{l}545.5 \\
{[3.3]}\end{array}$ & $\begin{array}{c}591.8 \\
{[4.6]}\end{array}$ & $\begin{array}{c}655.3 \\
{[3.6]}\end{array}$ & 0.24 \\
\hline
\end{tabular}

$\left({ }^{\mathrm{a}} \mathrm{Q}(0-0) /(\mathrm{Q}(1-0)=[\mathrm{Qy}(0-0)+\mathrm{Qx}(0-0)] /[\mathrm{Qy}(1-0)+\mathrm{Qx}(1-0)]\right.$ integrated intensity ratio $)$. 
Upon introduction of the halogen atoms at the paraposition of the meso-phenyl substituents, modest bathochromic shifts are observed in the ground state absorption spectra of the porphyrins. The nature of the halogen has a small, but distinct, effect on the observed red shift, the magnitude of which increases with increasing atomic number of the halosubstituent. Specifically, para-fluorination results in a red shift of only $0.1 \mathrm{~nm}$ for both the $\mathrm{H}_{2} \mathrm{TPP}$ and the ZnTPP, while the introduction of iodine atoms at the para-position of the meso-phenyl groups results in a greater red shift of $3 \mathrm{~nm}$ for the $\mathrm{H}_{2} \mathrm{TPP}$ and only $1.8 \mathrm{~nm}$ for the ZnTPP. Moreover, para-halogenation of the free-base and metallo-complex has a small effect on the intensity and width of the Q-bands. As shown in Fig. (2), panels $\mathrm{A}$ and $\mathrm{C}$, meso-halogenation progressively broadens the absorption and decreases the intensity of the $\mathrm{Q}(0-0)$ band (defined as $\mathrm{Q}_{\mathrm{x}}(0-0)+\mathrm{Q}_{\mathrm{y}}(0-0)$ for the free-base derivatives) as the atomic mass of the halosubstituent increases.

Table 2. Ground State Absorption Data of Metalloporphyrins in de-Aerated Benzene Solutions

\begin{tabular}{|c|c|c|c|c|}
\hline \multirow{2}{*}{ Porphyrin } & \multicolumn{3}{|c|}{ 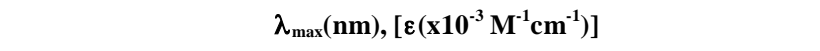 } & \multirow{2}{*}{$\mathbf{Q}(\mathbf{0 - 0}) /\left(\mathbf{Q}(\mathbf{1 - 0})^{\mathrm{a}}\right.$} \\
\hline & Soret or $\mathbf{B}(\mathbf{0 - 0})$ & $Q(1-0)$ & $Q(0-0)$ & \\
\hline ZnTPP & $\begin{array}{c}423.0 \\
{[545.0]}\end{array}$ & $\begin{array}{l}550.0 \\
{[26.7]}\end{array}$ & $\begin{array}{c}582.0 \\
{[6.0]}\end{array}$ & 0.22 \\
\hline ZnT(p-F-P)P & $\begin{array}{c}422.9 \\
{[551.1]}\end{array}$ & $\begin{array}{l}549.8 \\
{[26.9]}\end{array}$ & $\begin{array}{c}590.0 \\
{[5.7]}\end{array}$ & 0.21 \\
\hline $\mathrm{ZnT}$ (p-Cl-P)P & $\begin{array}{c}424.2 \\
{[542.8]}\end{array}$ & $\begin{array}{l}549.5 \\
{[27.2]}\end{array}$ & $\begin{array}{c}583.0 \\
{[5.4]}\end{array}$ & 0.20 \\
\hline ZnT(p-Br-P)P & $\begin{array}{c}424.0 \\
{[478.0]}\end{array}$ & $\begin{array}{l}549.0 \\
{[28.0]}\end{array}$ & $\begin{array}{c}582.0 \\
{[4.8]}\end{array}$ & 0.17 \\
\hline $\mathrm{ZnT}(\mathrm{p}-\mathrm{I}-\mathrm{P}) \mathbf{P}$ & $\begin{array}{c}424.8 \\
{[413.7]}\end{array}$ & $\begin{array}{l}549.0 \\
{[28.3]}\end{array}$ & $\begin{array}{c}582.0 \\
{[4.3]}\end{array}$ & 0.15 \\
\hline ZnT(p-Cl-P)P & $\begin{array}{c}424.2 \\
{[542.8]}\end{array}$ & $\begin{array}{l}550.0 \\
{[27.2]}\end{array}$ & $\begin{array}{c}583.0 \\
{[5.4]}\end{array}$ & 0.20 \\
\hline $\mathrm{ZnT}$ (m-Cl-P)P & $\begin{array}{c}423.8 \\
{[542.8]}\end{array}$ & $\begin{array}{l}549.5 \\
{[27.5]}\end{array}$ & $\begin{array}{l}583.0 \\
{[4.8]}\end{array}$ & 0.19 \\
\hline ZnT(o-Cl-P)P & $\begin{array}{c}427.4 \\
{[580.6]}\end{array}$ & $\begin{array}{l}549.5 \\
{[27.1]}\end{array}$ & $\begin{array}{c}581.0 \\
{[3.7]}\end{array}$ & 0.13 \\
\hline
\end{tabular}

( ${ }^{\mathrm{a}}$ Intensity ratio).
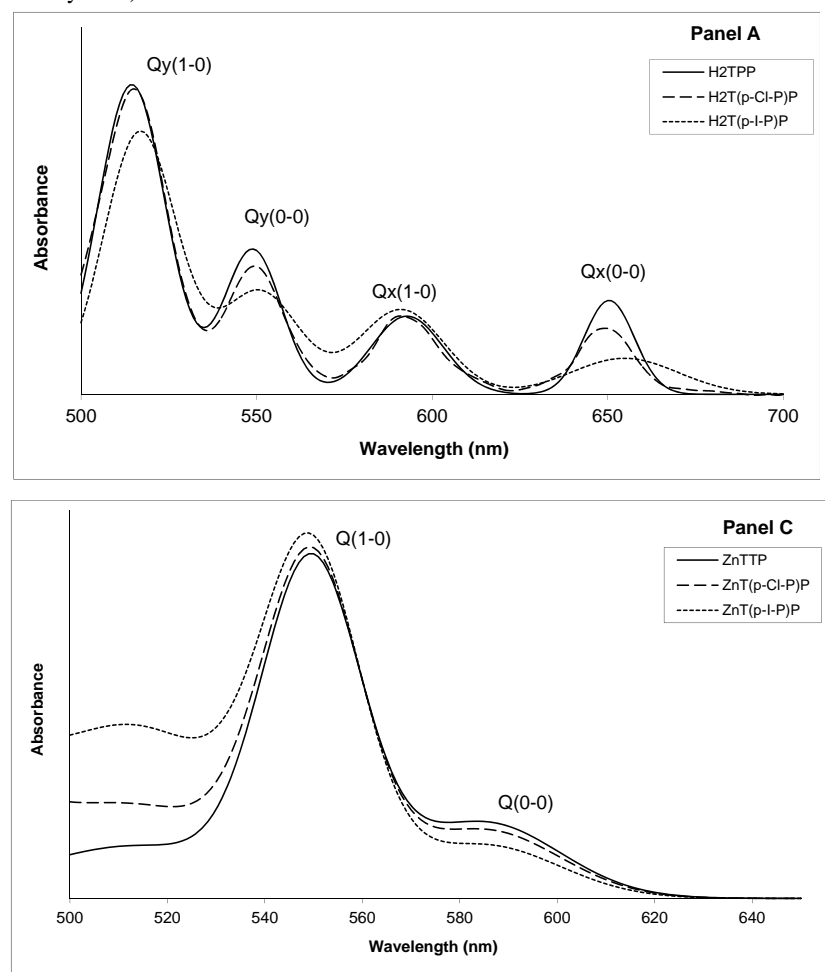
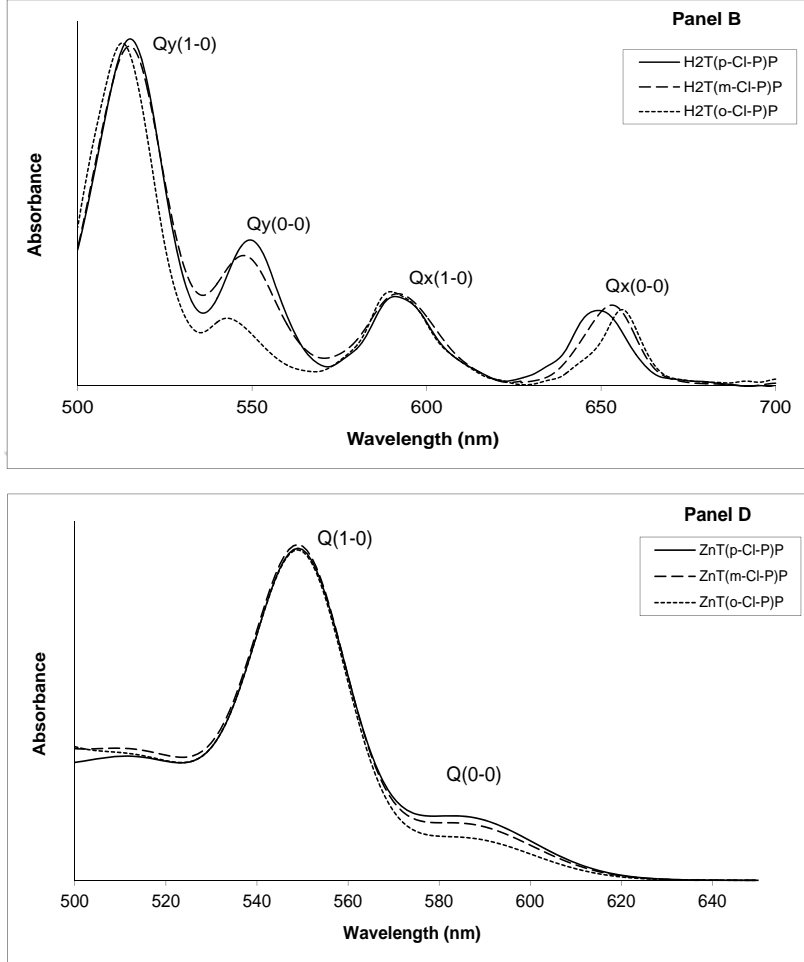

Fig. (2). Room-temperature Q-region ground state absorption spectra in benzene for a) $\mathrm{H}_{2} \mathrm{TPP}, \mathrm{H}_{2} \mathrm{~T}(\mathrm{p}-\mathrm{Cl}-\mathrm{P}) \mathrm{P}, \mathrm{H}_{2} \mathrm{~T}(\mathrm{p}-\mathrm{I}-\mathrm{P}) \mathrm{P}$; b) $\mathrm{H}_{2} \mathrm{~T}(\mathrm{p}-\mathrm{Cl}-$ P)P, $\mathrm{H}_{2} \mathrm{~T}$ (m-Cl-P)P, H $\mathrm{H}_{2} \mathrm{~T}$ (o-Cl-P)P; c) ZnTPP, ZnT(p-Cl-P)P, ZnT(p-I-P)P; d) ZnT(p-Cl-P)P ZnT(m-Cl-P)P, ZnT(o-Cl-P)P.

All spectra were normalized at $700 \mathrm{~nm}$. 
Chlorination at the meta- and ortho-positions does not follow the trend described above. A small blue shift of 0.3 $\mathrm{nm}$ for the $\mathrm{H}_{2}$ TPP and $0.6 \mathrm{~nm}$ for the ZnTPP is observed as the chlorine atoms are moved from the para- to the metaposition of the phenyl groups. Placement of chlorine at the ortho-position of the phenyl groups results in a greater blue shift of $1.7 \mathrm{~nm}$ (compared to the unsubstituted parent compounds) for the free-base porphyrin and a significant red shift of $3.2 \mathrm{~nm}$ for the zinc(II) porphyrin derivative.

\subsection{Steady-State and Time-Resolved Fluorescence Emission Spectroscopy}

Room temperature fluorescence emission spectra of the halogenated $\mathrm{H}_{2}$ TPP and ZnTPP series in de-aerated benzene are shown in Fig. (3). The spectra within each panel of Fig. (3) were recorded under identical conditions, including absorptivity at the excitation wavelength, reflecting the relative fluorescence emission quantum yields of the porphyrins. The fluorescence emission data, Stokes shifts $\left(\Delta_{\mathrm{SS}}, \mathrm{cm}^{-1}\right)$, lifetimes of the excited singlet excited state $\left(\tau_{\mathrm{s}}, \mathrm{ns}\right)$ for the freebase derivatives and the zinc(II) complexes are summarized in Tables $\mathbf{3}$ and $\mathbf{4}$ for the $\mathrm{H}_{2}$ TPP and ZnTPP derivatives, respectively. The fluorescence quantum yields $\left(\Phi_{\mathrm{Fl}}\right)$, summarized in Tables $\mathbf{3}$ and $\mathbf{4}$, were determined at room temperature in de-aerated benzene using the relative actinometry method [20]. The following equation was used to determine the quantum yields:

$$
\Phi_{x}=\Phi_{o} \frac{F_{x} A_{o} n_{x}^{2}}{F_{o} A_{x} n_{o}^{2}}
$$
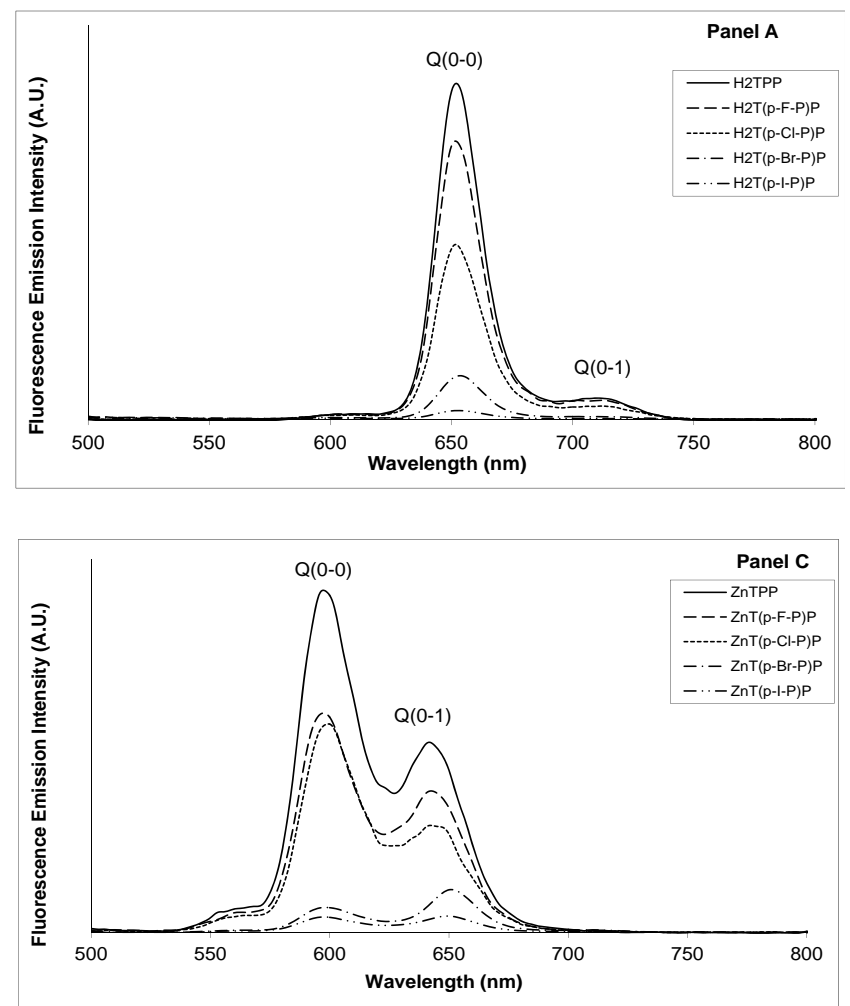

where $\mathrm{F}$ denotes the integral of the corrected fluorescence spectra, A is the absorbance at the excitation wavelength, and $\mathrm{n}$ is the refractive index of the medium. The subscripts " $\mathrm{x}$ " and "o" denote the sample and the reference compound, respectively. All samples were at excited at the Soret band at matched absorbance of O.D. less than 0.1.

The fluorescence emission spectra of all porphyrins show the $Q(0-0)$ and $Q(0-1)$ emission bands that are typical for porphyrins. Although halogenation of the free-base and zinc(II) porphyrins does not affect the fluorescence emission spectral profile with respect to the energy of the peaks, it has a profound effect on the relative intensities of the $\mathrm{Q}(0-0)$ and $\mathrm{Q}(0-1)$ bands in a way that reflects the changes observed for the same corresponding bands in the ground state absorption spectra.

The presence of the halogen on the meso-phenyl groups dramatically affects the magnitude of the derived fluorescence emission quantum yields and singlet excited state lifetimes without seriously affecting the magnitude of the Stokes shifts $\left(\Delta_{\mathrm{SS}}\right)$. Para-halogenation quenches the fluorescence emission of both the $\mathrm{H}_{2}$ TPP and ZnTPP progressively as the atomic number of the attached halogen increases. Introduction of iodine at the para-position almost completely quenches the fluorescence emission of both porphyrins. Furthermore, the immediacy of the halo-substituent to the $\pi$ system of the macrocycle has a significant effect on the quantum yields. Fairly small additional quenching is observed by moving the chlorine substituent from the para- to
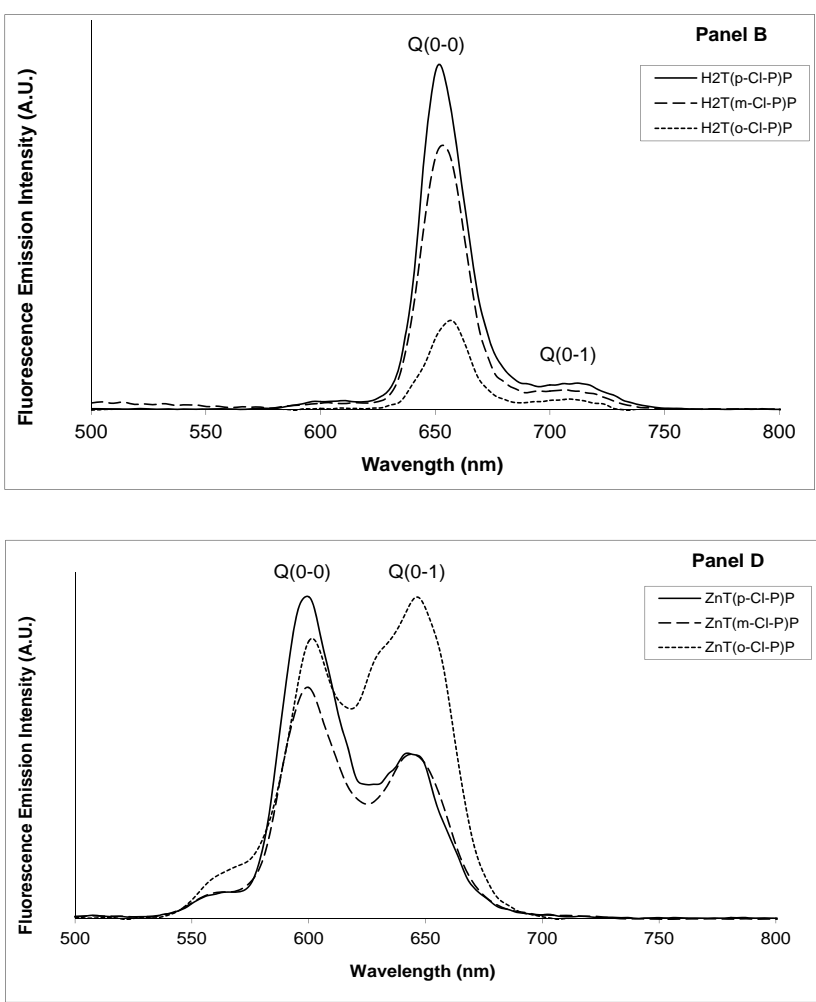

Fig. (3). Room-temperature corrected fluorescence spectra in de-aerated benzene for a) $\mathrm{H}_{2} \mathrm{TPP}, \mathrm{H}_{2} \mathrm{~T}(\mathrm{p}-\mathrm{F}-\mathrm{P}) \mathrm{P}, \mathrm{H}_{2} \mathrm{~T}(\mathrm{p}-\mathrm{Cl}-\mathrm{P}) \mathrm{P}, \mathrm{H}_{2} \mathrm{~T}(\mathrm{p}-\mathrm{Br}-\mathrm{P}) \mathrm{P}$, $\mathrm{H}_{2} \mathrm{~T}(\mathrm{p}-\mathrm{I}-\mathrm{P}) \mathrm{P} ;$ b) $\mathrm{H}_{2} \mathrm{~T}(\mathrm{p}-\mathrm{Cl}-\mathrm{P}) \mathrm{P}, \mathrm{H}_{2} \mathrm{~T}(\mathrm{~m}-\mathrm{Cl}-\mathrm{P}) \mathrm{P}, \mathrm{H}_{2} \mathrm{~T}(\mathrm{o}-\mathrm{Cl}-\mathrm{P}) \mathrm{P}$; c) ZnTPP, ZnT(p-F-P)P, ZnT(p-Cl-P)P, ZnT(p-Br-P)P, ZnT(p-I-P)P; d) ZnT(p-Cl-P)P, ZnT(m-Cl-P)P, ZnT(o-Cl-P)P.

Excitation took place in the Soret band.The spectra in each panel have been recorded under identical experimental conditions including absorption at the excitation wavelength. 
the meta-position of the free-base porphyrin and zinc(II) complex.

Contrastingly, ortho-chlorination has a significant and opposite effect on the emission properties of the unsubstituted parent porphyrins. Placement of chlorine atoms at the ortho-position decreases the fluorescence emission for $\mathrm{H}_{2}$ TPP and increases the fluorescence emission for ZnTPP. A similar increase in the fluorescence quantum yield of ZnTPP has been previously reported, but not justified, in the literature [21]. The lifetimes of the excited singlet state for the porphyrins were measured in de-aerated benzene. The values, which are summarized and presented in Tables $\mathbf{3}$ and $\mathbf{4}$, follow the trends observed for the emission quantum yields on a qualitative basis, but not on a qualitative basis. We were unable to measure the fluorescence lifetimes of the iodo-derivatives due to their low fluorescence emissions.

The porphyrins investigated in this study exhibit only modest Stokes shifts, in the range of $100 \mathrm{~cm}^{-1}$ for the freebase porphyrins and $500 \mathrm{~cm}^{-1}$ for the zinc(II) derivatives, which illustrates their low sensitivity to the nature of the halogen. The Stokes shifts are more sensitive to the position of the halogen. Shift of the chlorine substituents from the para- to the meta-positions and finally to the ortho-positions of the phenyl group, shows a distinct trend. For $\mathrm{H}_{2} \mathrm{TPP}$, the Stokes shifts decreased from 87 to $28 \mathrm{~cm}^{-1}$ and then went down to $7 \mathrm{~cm}^{-1}$ as the chlorine substituents were moved closer to the macrocycle. In the case of ZnTPP, the Stokes

Table 3. Luminescence Data of Free-Base Porphyrin in De-Aerated Benzene Solutions

\begin{tabular}{|c|c|c|c|c|c|c|c|c|c|}
\hline \multirow{2}{*}{ Porphyrin } & \multirow{2}{*}{$\mathbf{Q}(\mathbf{0 - 0})(\mathrm{nm})$} & \multirow{2}{*}{$Q(0-1)(n m)$} & \multirow{2}{*}{$Q(0-0) / Q(0-1)^{a}$} & \multirow{2}{*}{$\Delta_{\mathrm{SS}}\left(\mathrm{cm}^{-1}\right)^{\mathrm{b}}$} & \multirow{2}{*}{$\Phi_{\mathrm{F} 1}$} & \multirow{2}{*}{$\tau_{\mathrm{s}}(\mathbf{n s})$} & \multicolumn{2}{|c|}{$k_{F 1}\left(x 10^{-6} s^{-1}\right)$} & \multirow{2}{*}{$\begin{array}{c}k_{\mathrm{ISC}} \\
\left(\mathbf{x} 10^{-8} \mathrm{~s}^{-1}\right)\end{array}$} \\
\hline & & & & & & & Exp. ${ }^{c}$ & Calc. $^{d}$ & \\
\hline $\mathbf{H}_{2} \mathbf{T}(p-F-P) P$ & 652.6 & 679.3 & 2.86 & 14.1 & 0.097 & 10.8 & 9.0 & 8.5 & 0.16 \\
\hline $\mathbf{H}_{2} \mathbf{T}(\mathbf{p}-\mathbf{B r}-\mathbf{P}) \mathbf{P}$ & 654.0 & 670.4 & 2.14 & 56.3 & 0.016 & 2.2 & 7.3 & 7.7 & 3.78 \\
\hline $\mathbf{H}_{2} \mathbf{T}(\mathbf{p}-\mathrm{I}-\mathrm{P}) \mathbf{P}$ & 654.0 & 688.7 & 1.30 & 0.0 & 0.005 & $--^{\mathrm{e}}$ & $--^{\mathrm{e}}$ & 6.5 & $--^{\mathrm{e}}$ \\
\hline $\mathbf{H}_{2} \mathbf{T}(\mathbf{p}-\mathrm{Cl}-\mathrm{P}) \mathbf{P}$ & 652.9 & 678.8 & 2.44 & 87.3 & 0.063 & 8.2 & 7.7 & 7.9 & 0.45 \\
\hline
\end{tabular}

$\left({ }^{\mathrm{a}}\right.$ Intensity ratio; ${ }^{\mathrm{b}} \mathrm{Qx}(0-0)$ absorption/emission "Stokes" Shift; ${ }^{\mathrm{c}} \mathrm{k}_{\mathrm{Fl}}=\Phi_{\mathrm{Fl}} / \tau_{\mathrm{S}} ;{ }^{\mathrm{d}}$ Calculated using the modified Strickler-Berg equation; ${ }^{\mathrm{e}}$ Lifetime has not been determined due to the low fluorescence emission of the compound).

Table 4. Luminescence Data of Metalloporphyrins in De-Aerated Benzene Solutions

\begin{tabular}{|c|c|c|c|c|c|c|c|c|c|}
\hline \multirow{2}{*}{ Porphyrin } & \multirow{2}{*}{$\mathbf{Q}(\mathbf{0 - 0})(\mathbf{n m})$} & \multirow{2}{*}{$Q(0-1)(n m)$} & \multirow{2}{*}{$\mathbf{Q}(0-0) / Q(0-1)^{a}$} & \multirow{2}{*}{$\Delta_{\mathrm{SS}}\left(\mathrm{cm}^{-1}\right)^{\mathbf{b}}$} & \multirow{2}{*}{$\Phi_{\mathrm{Fl}}$} & \multirow{2}{*}{$\tau_{\mathrm{S}}(\mathbf{n s})$} & \multicolumn{2}{|c|}{$k_{F 1}\left(x 10^{-6} s^{-1}\right)$} & \multirow{2}{*}{$\begin{array}{c}k_{I S C} \\
\left(\times 10^{-8} s^{-1}\right)\end{array}$} \\
\hline & & & & & & & Exp. ${ }^{\mathrm{c}}$ & Calc. $^{d}$ & \\
\hline ZnTPP & 598.5 & 640.8 & 1.31 & 473.7 & 0.033 & 2.0 & 16.5 & 14.0 & \\
\hline ZnT(p-F-P)P & 598.3 & 641.7 & 1.19 & 235.1 & 0.023 & 1.5 & 15.3 & 13.9 & 1.67 \\
\hline $\mathrm{ZnT}(\mathbf{p}-\mathrm{Br}-\mathrm{P}) \mathbf{P}$ & 601.2 & 651.1 & 0.72 & 548.7 & 0.004 & 0.8 & 5.0 & 8.9 & 7.50 \\
\hline $\mathbf{Z n T}(\mathbf{p}-\mathrm{I}-\mathbf{P}) \mathbf{P}$ & 599.8 & 648.5 & 0.91 & 509.9 & 0.002 & $--^{e}$ & $--^{e}$ & 7.3 & $--^{\mathrm{e}}$ \\
\hline ZnT(p-Cl-P)P & 599.5 & 641.1 & 1.37 & 472.1 & 0.020 & 1.4 & 14.3 & 14.5 & 2.14 \\
\hline
\end{tabular}

$\left({ }^{\mathrm{a}}\right.$ Intensity ratio; ${ }^{\mathrm{b}} \mathrm{Qx}(0-0)$ absorption/emission "Stokes" shift; ${ }^{\mathrm{c}} \mathrm{k}_{\mathrm{Fl}}=\Phi_{\mathrm{F} /} / \tau_{\mathrm{S}} ;{ }^{\mathrm{d}}$ Calculated using the modified Strickler-Berg equation; ${ }^{\mathrm{e}}$ Lifetime has not been not determined due to the low fluorescence emission of the compound). 
shifts increased from 472 to $486 \mathrm{~cm}^{-1}$, and finally went up to $653 \mathrm{~cm}^{-1}$, as the chlorine substituents were moved from the para- to the meta- and then to the ortho-position of the meso-phenyl group.

The natural radiative rate constants $\left(\mathrm{k}_{\mathrm{Fl}}\right)$ were determined from the experimental data and calculated from the absorption and fluorescence spectra using the modified StricklerBerg [22] equation:

$$
k_{F l}=2.88 \times 10^{-9} n^{2} \frac{\int F(v) d v}{\int \frac{F(v)}{v^{3}} d v} \int \frac{\varepsilon(v)}{v} d v
$$

where $F(v)$ and $\varepsilon(v)$ denote the emission intensity and molar absorption coefficient respectively, at wavenumber $v\left(\mathrm{~cm}^{-1}\right)$, and $\mathrm{n}$ is the refractive index of the solvent. The values derived above are summarized in Tables $\mathbf{3}$ and $\mathbf{4}$, and they are consistent with the experimental values $\left(\mathrm{k}_{\mathrm{Fl}}=\Phi_{\mathrm{Fl}} / \tau_{\mathrm{S}}\right)$. The $\mathrm{k}_{\mathrm{Fl}}$ values decrease upon halogenation of either parent porphyrin, following the trends observed for the quantum yields and fluorescence emission lifetimes.

\subsection{Determination of the Singlet Oxygen Generation Quantum Yields}

The singlet oxygen generating efficiencies of the chromophores were determined using DMA photobleaching assays, monitored by UV-Vis spectroscopy at $401 \mathrm{~nm}$. DMA as an $\mathrm{O}_{2}\left({ }^{1} \Delta_{\mathrm{g}}\right)$ captor was well suited for our experiments, since it reacts quickly, qualitatively and selectively with the species generated by the photosensitized singlet oxygen. Also, it is photostable under the experimental conditions, and its absorption spectrum does not interfere with that of the porphyrin based PS [23].

The $\Phi_{\Delta}$ of the chromophores were estimated by comparison of the slope of a linear-square fit to that obtained for the reference chromophore $\left(\Phi_{\Delta}\left(\mathrm{H}_{2} \mathrm{TPP}\right)=0.63\right)$ under identical conditions. The $\Phi_{\Delta}$ values are summarized in Table 5. Control experiments indicate no DMA photobleaching by the PS in the absence of both the light source and atmospheric oxygen (under argon). Moreover, no photobleaching was observed when DMA was irradiated in equilibrium with the atmosphere in the absence of a PS. Furthermore, the fact that the ground state absorption spectra of DMA/PS solution is superposable on the mathematical addition of the spectra of the separate components indicating that no chemical reaction takes place between the PS and the oxygen captor in toluene.

\section{DISCUSSION}

The selection of porphyrins as photosensitizing agents requires knowledge of their photophysical properties. We utilized $\mathrm{H}_{2}$ TPP and ZnTPP to demonstrate the effects of halogenation at the meso-phenyl groups on the electronic properties of the ground state and the excited state and to demonstrate the significance of the halogenation on the singlet oxygen generation quantum yields.

According to the four-orbital model [19], the position and intensity of porphyrin absorption bands are determined by the relative energies of the transitions between the HOMO $\left(\mathrm{a}_{1 \mathrm{u}}(\pi)\right.$ and $\mathrm{a}_{2 \mathrm{u}}(\pi)$ ) and the LUMO (a set of degenerate $\mathrm{e}_{\mathrm{g}}\left(\pi^{*}\right)$ ) of the porphyrin. As the electronic transition energies $\mathrm{E}\left(\mathrm{a}_{1 \mathrm{u}} \rightarrow \mathrm{e}_{\mathrm{g}}\right)$ and $\mathrm{E}\left(\mathrm{a}_{2 \mathrm{u}} \rightarrow \mathrm{e}_{\mathrm{g}}\right)$ become equal, the $\mathrm{Q}(0-0)$ band
Table 5. Singlet Oxygen Generation Quantum Yields Measured Photolytically in Air-Saturated Toluene Solutions using DMA as Target

\begin{tabular}{|c|c|c|}
\hline \multirow{2}{*}{ Porphyrin } & \multicolumn{2}{|c|}{$\Phi_{\Delta}$} \\
\hline & $\mathbf{M}: \mathbf{2} \mathbf{H}^{+}$ & $\mathbf{M}: \mathbf{Z n}^{2+}$ \\
\hline MTPP & 0.63 & 0.78 \\
\hline MT(p-F-P)P & $\begin{array}{c}0.67 \\
(6.35 \%)^{\mathrm{a}}\end{array}$ & $\begin{array}{c}0.89 \\
(14.10 \%)^{\mathrm{b}}\end{array}$ \\
\hline MT(p-Cl-P)P & $\begin{array}{c}0.69 \\
(9.52 \%)^{\mathrm{a}}\end{array}$ & $\begin{array}{c}0.93 \\
(19.23 \%)^{\mathrm{b}}\end{array}$ \\
\hline MT(p-Br-P)P & $\begin{array}{c}0.73 \\
(15.87 \%)^{\mathrm{a}}\end{array}$ & $\begin{array}{c}0.96 \\
(23.08 \%)^{\mathrm{b}}\end{array}$ \\
\hline MT(p-I-P)P & $\begin{array}{c}0.88 \\
(39.68 \%)^{\mathrm{a}}\end{array}$ & $\begin{array}{c}1.00 \\
(28.21 \%)^{\mathrm{b}}\end{array}$ \\
\hline MT(p-Cl-P)P & 0.69 & 0.93 \\
\hline MT(m-Cl-P)P & $\begin{array}{c}0.70 \\
(1.45 \%)^{\mathrm{c}}\end{array}$ & $\begin{array}{c}0.88 \\
(-5.38 \%)^{d}\end{array}$ \\
\hline MT(o-Cl-P)P & $\begin{array}{c}0.72 \\
(4.35 \%)^{\mathrm{c}}\end{array}$ & $\begin{array}{c}0.79 \\
(-15.05 \%)^{\mathrm{d}}\end{array}$ \\
\hline
\end{tabular}

( ${ }^{\mathrm{a}} \%$ increase compared to $\mathrm{H}_{2} \mathrm{TPP} ;{ }^{\mathrm{b}} \%$ increase compared to ZnTPP; ${ }^{\mathrm{c}} \%$ increase compared to $\mathrm{H}_{2} \mathrm{~T}(\mathrm{p}-\mathrm{Cl}-\mathrm{P}) \mathrm{P}$; ${ }^{\mathrm{d}} \%$ decrease compared to $\left.\mathrm{ZnT}(\mathrm{p}-\mathrm{Cl}-\mathrm{P}) \mathrm{P}\right)$.

loses intensity. The relative energies of the HOMO $\mathrm{a}_{1 \mathrm{u}}(\pi)$ and $\mathrm{a}_{2 \mathrm{u}}(\pi)$ orbitals depend on the structure of the porphyrin, although, for both the $\mathrm{H}_{2}$ TPP and ZnTPP, the $\mathrm{a}_{2} \mathrm{u}(\pi)$ lies energetically above the $\mathrm{a}_{1 \mathrm{u}}(\pi)$ [24].

Based on local density functional electronic calculations [25], the $\mathrm{a}_{2 \mathrm{u}}$ molecular orbital places electron density at the meso-carbons of the porphyrin, while the $\mathrm{a}_{1 \mathrm{u}}$ molecular orbital places energy at the $\alpha$ - and $\beta$-pyrrole carbons. In general, halogenation of porphyrins results in energy reduction for both the HOMO and LUMO, since the electronegative halogen atoms reduce the electron density of the porphyrin $\pi$-system. With regards to the HOMO, molecular orbital nodal properties predict a more severe effect on the $\mathrm{a}_{2 u}$ orbital relative to the $\mathrm{a}_{1 \mathrm{u}}$ upon halogenation of the meso-phenyl groups of tetraarylporphyrins (TPP). On the other hand, the interaction of any substituent with the degenerate set of LUMO is symmetrical and does not alter the energy of the electronic transitions $\mathrm{E}\left(\mathrm{a}_{1 \mathrm{u}} \rightarrow \mathrm{e}_{\mathrm{g}}\right)$ and $\mathrm{E}\left(\mathrm{a}_{2 \mathrm{u}} \rightarrow \mathrm{e}_{\mathrm{g}}\right)$. Consequently, placement of a halogen on the meso-phenyl substituents of $\mathrm{H}_{2}$ TPP and ZnTPP brings the $\mathrm{a}_{2 \mathrm{u}}$ orbital closer in energy to the $a_{1 u}$ orbital and narrows the energy gap between the $\mathrm{E}\left(\mathrm{a}_{1 \mathrm{u}} \rightarrow \mathrm{e}_{\mathrm{g}}\right)$ and $\mathrm{E}\left(\mathrm{a}_{2 \mathrm{u}} \rightarrow \mathrm{e}_{\mathrm{g}}\right)$ transitions. Such an effect on the molecular orbital system of the porphyrin will result in a reduced intensity for the $\mathrm{Q}(0-0)$ absorption band. On the other hand, halogenation of a porphyrin is not expected to alter the intensity of the $\mathrm{Q}(1-0)$ band, since the band gets its intensity from vibronic mixing with the Soret band. In other words, changes in the intensity of the $\mathrm{Q}(0-0)$ absorption band, relative to the $\mathrm{Q}(1-0)$ band, may provide a measure of the energy gap between the $\mathrm{a}_{1 \mathrm{u}}$ and $\mathrm{a}_{2 \mathrm{u}}$ orbitals and the extent of interaction between exocyclic halo-substituents and the $\pi$ - 
system of the macrocycle. In our experiments, we have utilized the intensity ratio, $\mathrm{Q}(0-0) / \mathrm{Q}(1-0)$, to gain insight into the effects of halogenation on the electronic properties of $\mathrm{ZnTPP}$ and $\mathrm{H}_{2}$ TPP.

Para-halogenation reduces the $\mathrm{Q}(0-0) / \mathrm{Q}(1-0)$ intensity ratio, suggesting stabilization of the $\mathrm{a}_{2 \mathrm{u}}$ orbital upon halogenation. Halogens on the meso-phenyl groups of a porphyrin may interact indirectly with the $\pi$-system of the macrocycle either through conjugation, via the phenyl $\pi$-system, or inductively, via the phenyl $\sigma$-bond framework. Our experimental data indicate that para- and meta-halogenation affects the photophysics of the molecule via conjugative effects, mediated by the $\pi$-system of the meso-phenyl group, since the less electronegative iodine substituents are more effective in lowering the energy of the $\mathrm{a}_{2 u}$ orbital than the more electronegative fluorine atoms. Additional support for a conjugative interaction between the para-positioned halosubstituents and the macrocycle is provided by the greater red shift of 2-3 nm observed in the absorption spectra of the para-iodo derivatives compared to the red shift of less than $0.1 \mathrm{~nm}$ observed for the case of the para-fluoro derivatives. It seems that, for the case of the iodo-derivatives, the phenyl groups adopt a more planar conformation to allow a more extended conjugation between the para-positioned iodine atoms and the macrocycle. However, overall, the effects of the para- and meta-halogenation on the absorption spectra of the porphyrins are limited due to steric factors that allow only partial conjugation between the halo-substituent and the macrocycle. The X-ray crystallographic structure of $\mathrm{H}_{2} \mathrm{TPP}$ [26] shows the meso-phenyl substituents to be out of the plane of the porphyrin $\pi$-system by an average dihedral angle of $60^{\circ}$, with NMR studies indicating a rotational barrier of $11-17 \mathrm{kcal} / \mathrm{mol}$ [27].

On the other hand, meta-chlorination results in a small, but distinct, blue shift in the ground state absorption spectra of the porphyrins compared to the para-chlorinated analogue. We attribute the observed blue shift to steric factors between the meta-positioned halogen and the pyrrole $\beta-\mathrm{H}$ that result in an increased dihedral angle between the phenyl group and the macrocycle and, consequently, reduced conjugation between the electronegative halogen atom and the macrocycle. The small red shift observed in the absorption spectra of the meta-chlorinated derivatives, with respect to the unsubstituted parent compounds, suggests that the phenyl group is not perpendicular to the plane of the molecule, an arrangement that would electronically isolate the chlorosubstituent from the macrocycle.

Ortho-halogenation seems to facilitate a different kind of interaction between the halo-substituent and the $\pi$-system of the macrocycle. The placement of substituents at the orthoposition of the meso-phenyl group is a classical approach for locking the porphyrin and the aryl units in a perpendicular arrangement [28], inhibiting indirect conjugation between the induced electron-withdrawing halogens and the porphyrin ring. Despite the obvious steric effects, our experimental data indicate that there is strong electronic communication between the ortho-chlorine and the $\pi$-system of the macrocycle. Density functional calculations, photophysical experiments, and EPR experiments predict direct overlap between the non-bonding $2 \mathrm{p}$ orbitals of the ortho-chlorine sub- stituent and the $\pi$-system of the macrocycle, both at the $\beta$ pyrrole and meso-carbon of the porphyrin [21, 25b, 29].

From a spectroscopic standpoint, orbital overlap of an ortho-halo substituent with the $\beta$-pyrrole carbons will result in the stabilization of the $\mathrm{a}_{1 \mathrm{u}}$ orbital and widening of the energy gap between the HOMO orbitals, translating into an increase for the $\mathrm{Q}(0-0)$ absorption band. On the other hand, overlap with the meso-carbon will result in stabilization of the $a_{2 u}$ orbital, leading to a reduction in the intensity of the $\mathrm{Q}(0-0)$ absorption band. Based on our data, the significantly reduced intensity of the $\mathrm{Q}(0-0)$ absorption band suggests that there is a strong interaction between the ortho-chloro substituent and the meso-carbon of the macrocycle. A possible overlap between the halogen's $2 p$ orbital and the $\beta$-pyrrole carbon should not be ruled out. However, such an interaction is limited, particularly in the case of the relatively small chlorine atom. For the sake of argument, a vastly larger atom, such as iodine, at the ortho-position may have a greater overlap with the $\beta$-pyrrole carbon.

The observed reduction in the fluorescence quantum yield may not be attributed to a possible conformational distortion caused by the halogen substitutions as the mirror image relationship between the fluorescence spectra. The relevant portion of the absorption spectra supports the absence of substantial geometric changes upon excitation. Further support for the absence of conformational distortions is provided by the small Stokes shifts $\left(\Delta_{\mathrm{SS}}\right)$ of less than $100 \mathrm{~cm}^{-1}$ for the $\mathrm{H}_{2}$ TPP halo-derivatives and $500 \mathrm{~cm}^{-1}$ for the corresponding ZnTPP derivatives.

The dependence of the observed fluorescence quenching on the nature of the halo-substituent is consistent with the principles of the heavy atom effect. Among the parahalogenated series, the fluorine has the least effect on the fluorescence quantum yields, while the introduction of iodosubstituents has the most profound effect on the quantum yield of both the free-base and zinc(II) complexes. The heavy atom effect is associated with an increase in the probability of intercombination conversions, i.e., $S_{1} \sim>T_{1}, T_{1} \sim>S_{0}$, and $\mathrm{T}_{1} \rightarrow \mathrm{S}_{0}$. According to the intercombination selection rule, electronic transitions between states of different multiplicity within a molecule are spin-forbidden processes and, as such, have low probability. Spin-orbit perturbation, promoted by the presence of a heavy atom in the environment of the chromophore, may increase the rate of spin-forbidden processes [30] and allow intercombination transitions. Such a perturbation would arise from the coupling of the electron's spin and the relativistic magnetic field induced by its orbital motion.

The effect of a heavy atom on the luminescence properties of a molecule is well known and longstanding. The heavy atom may be either chemically attached to the chromophore (internal heavy atom effect) or in the composition of the solvent (external heavy atom effect). The study of naphthalene and its halo derivatives is a classic example of the heavy atom effect and is closely related to our porphyrinbased chromophores [31].

The internal heavy atom effect has been a conventional strategy for populating the triplet-excited state of a chromophore [32], again a desirable photophysical property of po- 
tent triplet state PSs. According to the classical theoretical model [33], incorporation of heavy atoms into a chromophore promotes ISC by promoting spin-orbit coupling. The magnitude of the effect depends on the atomic spin-orbit coupling constant of the heavy atom $(\xi)$ and the atomic orbital coefficients (c) for coupling between the heavy atom and the chromophore at the excited state. The following equation relates the rate constant for intersystem crossing, $\mathrm{k}_{\mathrm{ISC}}$, to $\xi$ :

$$
k_{I S C}=B\left(C_{C} C_{H}\right)^{a}\left(\sum_{x} \xi_{x}^{a}\right)
$$

Here, B denotes the unsubstituted inherent rate constant for ISC, the $\alpha$-value represents the extent of the heavy atom effect and takes values from $0-2, \chi$ is the number of halogen atoms attached to the chromophore, and $\mathrm{C}_{\mathrm{C}}$ and $\mathrm{C}_{\mathrm{H}}$ are the atomic orbital coefficients for the substituted carbon atom in the excited state and the halogen atom, respectively. For substitution at a fixed site, the atomic orbital coefficients are assumed to be constant and variations in the rate constant for intersystem crossing $\left(\mathrm{k}_{\mathrm{ISC}}\right)$ can be expressed in terms of $\xi$. Thus, for the para-halogenated chromophores, the above equation can be simplified to:

$k_{I S C}=4 B\left(C_{C} C_{H}\right)^{a} \xi^{a} \Rightarrow \log \left(k_{I S C}\right)=\log ($ const.$)+a \log (\xi)$

In turn, the intersystem crossing rate constants $\left(\mathrm{k}_{\text {ISC }}\right)$ of the substituted chromophores can be calculated according to the equation:

$$
k_{I S C}=\frac{1}{\tau_{0}}-\frac{1}{\tau_{H}}
$$

Here, $\tau_{0}$ and $\tau_{\mathrm{H}}$ denote the lifetimes of the excited singlet state for the unsubstituted (intrinsic lifetime) and substituted chromophores, respectively.

For the purpose of this study, various degrees of spinorbit coupling have been used to exploit its significance on the singlet oxygen generation yield of the porphyrin-based PSs. To better understand the phenomena involved, we have investigated both the endocyclic heavy atom effect, by plac- ing a zinc atom at the center of the porphyrin, and the exocyclic heavy atom effect, by placing heavy halogen atoms at the periphery of the chromophore.

Based on equation 4 , the $\mathrm{k}_{\mathrm{ISC}}$ values for the parasubstituted porphyrins have been calculated (Tables 3 and 4) and plotted against the atomic spin-orbit coupling constants for the halogens (Fig. 4). The linear relationships obtained for the para-halogenated $\mathrm{H}_{2}$ TPP and ZnTPP derivatives suggest that spin-orbit coupling is the sole phenomenon responsible for the observed changes in the photophysics of the chromophores. The graph produces a slope of 1.45 for the $\mathrm{H}_{2} \mathrm{TPP}$ and 0.71 for the ZnTPP derivatives. The experimental values indicate that halogenation of the $\mathrm{H}_{2} \mathrm{TPP}$ has a more pronounced effect on the photophysical properties of the chromophore than for the case of the ZnTPP, wherein the Zn heavy atom is already present. The relatively high $\alpha$-value of 1.45 , associated with para-halogenation of the $\mathrm{H}_{2} \mathrm{TPP}$, indicates strong electron communication between the porphyrin and the para-positioned halogens, although the value is lower than the maximum allowed value of 2.0 obtained for the case of the 1-halonaphthalene series [31].

The reason for the reduced $\alpha$-value in the case of the $\mathrm{H}_{2}$ TPP halo-derivatives is the partial conjugation of the halosubstituents with the $\pi$-system of the porphyrin. The out-ofplane orientation of the phenyl ring with respect to the plane of the molecule is the main reason for the observed reduced $\alpha$-value. We attribute the lower derived $\alpha$-value in the case of the metallated series to the electron withdrawing effect of the para-positioned halo-substituents. We believe that, in the case of the zinc (II) complex, the exocyclic and the endocyclic heavy atom effects oppose each other. Para-halogenation seems to withdraw electron density from the macrocycle, weakening the electrostatic interaction between the macrocycle and the central metal, zinc(II), and, subsequently, weakening the endocyclic heavy atom effect.

Additional support for the opposing effect of the exocyclic halogen atoms on the spin-orbit coupling capability of the endocyclic heavy zinc atom comes from the surprisingly

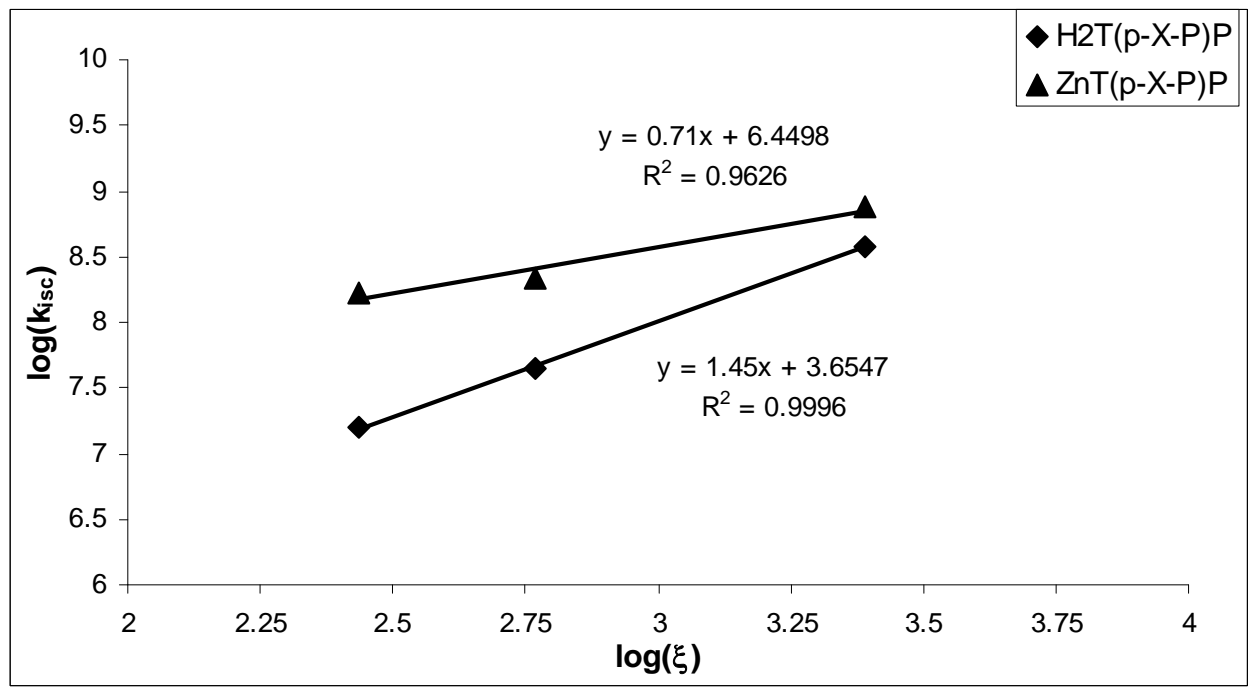

Fig. (4). Double-logarithmic plot of the rate constant intersystem crossing $\left(\mathrm{k}_{\mathrm{ISC}}\right)$ with the atomic spin-orbit coupling constants $(\xi)$. ( $\left.\mathbf{\Delta}\right)$ parahalogenated ZnTPP derivatives ( ) para-halogenated $\mathrm{H}_{2}$ TPP derivatives. Literature values $\xi(\mathrm{F})=272 \mathrm{~cm}^{-1}, \xi(\mathrm{Cl})=587 \mathrm{~cm}^{-1}, \xi(\mathrm{Br})=2460 \mathrm{~cm}^{-1}$ [34]. 
high quantum yield of the ortho-chlorinated ZnTPP derivative. The observed increase agrees with previously reported experimental findings $[29 \mathrm{~b}, \mathrm{c}]$. As discussed earlier, placement of the chloro-substituent at the ortho-position facilitates overlap of the $2 \mathrm{p}-\mathrm{Cl}$ orbital with the $\pi$-orbital of the meso-carbon. The strong interaction of the electronegative atom with the macrocycle significantly reduces the electronegativity of the macrocycle and the interaction with the central metal, resulting in reduction of the endocyclic heavy atom effect. For reasons as yet to be explained, the heavy atom effect of the ortho-halogenated ZnTPP is surprisingly higher than that of the $\mathrm{H}_{2}$ TPP analogue.

According to the classical model of the heavy atom effect, the observed decrease in fluorescence quantum yield for the halogenated porphyrin derivatives is associated with the observed decrease in the natural radiative rate constant. The latter effect is due to the increasing rate of the non-radiative decay pathways at the excited triplet state. The natural fluorescence rate constants, summarized in Tables $\mathbf{3}$ and $\mathbf{4}$, document this trend. The $\mathrm{k}_{\mathrm{Fl}}$ of the para-iodo derivatives are significantly lower than those of the corresponding unsubstituted compounds $\mathrm{H}_{2}$ TPP and ZnTPP. The measured lifetimes of the halogenated derivatives follow qualitatively the trend of the fluorescence quantum yields. The ratio $\Phi_{\mathrm{Fl}} / \tau_{\mathrm{s}}$ for the halo-derivatives is not constant; it decreases as the atomic number of the halogen attached to the macrocycle increases.

The final step that leads to the formation of singlet oxygen is energy transfer from the triplet state of a PS to the ground state of molecular oxygen. High triplet state quantum yields and long triplet state lifetimes are desired properties for prospective singlet oxygen PSs. An increase in the probability of the intercombination conversion $S_{1} \sim>T_{1}$ induced by a heavy atom has been a classical approach to increase the triplet state quantum yields of potential singlet oxygen PSs. However, an increase in the non-radiative internal conversion from the chromophore's excited triplet state to the ground state $\left(\mathrm{T}_{1} \sim>\mathrm{S}_{0}\right)$ may poison singlet oxygen generation yields. In that case, the heavy atom effect will result in a decrease in the fluorescence quantum yield and the singlet oxygen generation quantum yield for the PS. Studies of tetraarylazadipyrromethene derivatives have shown that the position of the heavy atom significantly affects the rate of the non-radiative internal conversion $\mathrm{T}_{1} \sim>\mathrm{S}_{0}$ [34]. Our study on tetraarylporphyrins indicate the same trend.

Using DMA photobleaching assays, we have determined the singlet oxygen-quantum yields of the halogenated $\mathrm{H}_{2}$ TPP and ZnTPP derivatives. The experiments were designed to illustrate the effects of the halogen type and its relative position with respect to the macrocycle on the singlet oxygen quantum yields. Our data indicate that the para-exocyclic heavy atom effect enhances the singlet oxygen quantum yield of both free-base and the zinc(II) complex. The singlet oxygen quantum yield of the $\mathrm{H}_{2} \mathrm{TPP}$ series ranges from 0.63 (for the unsubstituted parent compound) to 0.88 (for the iodo-derivative). A similar but less important increase in the singlet oxygen quantum yield of the ZnTPP analogues is observed; a value of 0.78 was obtained for the unsubstituted ZnTPP, and a value of 1.00 was obtained for the corresponding para-iodo-derivative.
Moreover, the proximity of the heavy atom to the macrocycle also seems to have a profound effect on the singlet oxygen quantum yields. Shifting the chloro-substituent from the para- to the meta-position of the phenyl groups leads to a small increase in the singlet oxygen quantum yield for the $\mathrm{H}_{2}$ TPP derivatives. Placement of the chloro-substituents at the ortho-position increases even more the ability of the chromophore to generate singlet oxygen even more, indicating that orbital overlap between the halo-substituent and the $\pi$-system of the macrocycle favors ISC. Taking into consideration that shift of the chorine atoms from the para- to the ortho-position leads to $81 \%$ decrease in fluorescence quantum yield and only $4 \%$ increase in the singlet oxygen generation, it seems that the orbital direct orbital overlap between the halo-substituent and the macrocycle significantly increases the rate of the non-radiative internal conversion from the triplet state, $\mathrm{T}_{1} \sim>\mathrm{S}_{0}$, a decay pathway that leads to depopulation of the triplet state.

On the other hand, the singlet oxygen quantum yields of the halogenated ZnTPP derivatives tend to be more sensitive to the position of the halo-substituent on the meso-phenyl group. Shifting the chlorine atoms from the para- to the ortho- position leads to a decrease in the singlet oxygen quantum yield of $15 \%$ and an increase in the fluorescence quantum yield of $35 \%$. In accordance with earlier findings, here the exocyclic heavy atom effect reverses the endocyclic effect, resulting in a decrease of the non-radiative decay pathway from the triplet state, $\mathrm{T}_{1} \sim>\mathrm{S}_{0}$.

\section{CONCLUSIONS}

The study reported herein has explored how halogenation of tetraarylporphyrins can be used to tune the electronic properties of the ground state and excited state in order to enhance the ability of the chromophore to sensitize singlet oxygen. By halogenation of the meso-phenyl groups, we have been able to manipulate the energy spacing and electron density distribution for the $\mathrm{a}_{1 \mathrm{u}}$ and $\mathrm{a}_{2 \mathrm{u}}$ orbitals, excited state quantum yields, and lifetimes, as well as the capability of porphyrin-based PSs to generate singlet oxygen.

The experimental data indicate that placement of heavy halogen atoms at either the para- or meta- position of the meso-phenyl substituents of the free-base and zinc(II) porphyrins enhances the ability of the chromophores to generate singlet oxygen. The magnitude of the effect is influenced by both the nature and the proximity of the halo-substituent. However, the halogen substituent effect seems to offset the endocyclic heavy atom effect induced by the central zinc(II).

Placement of the halo-substituents at the ortho-position of the phenyl groups enables direct orbital overlap between the halo-substituent and the macrocycle, making them a different class of compounds with a completely new set of chemical and physical properties [35]. For the case of the free-base porphyrin, ortho-chlorination further increases the ability of the chromophore to generate singlet oxygen. On the other hand, ortho-chlorination reduces the ability of the ZnTPP to generate singlet oxygen, substantiating our initial premise that implementation of the halogen substituent effect 
in an attempt to enhance the singlet oxygen quantum yield of a chromophore should be done cautiously.

Finally, the data indicate that the $\mathrm{H}_{2} \mathrm{TPP}$ and ZnTPP derivatives employed in this study have sufficiently long triplet excited state lifetimes to sensitize efficiently the formation of singlet oxygen. However, the porphyrin derivatives employed in this study are not expected to have the desired solubility or affinity for oncogenic cells, and they were not studies as such. However, the porphyrin derivates used in the study do have the required photophysical properties, and may serve as suitable templates for the synthesis of appropriately functionalized PDT agents.

\section{SUPPORTING INFORMATION}

Supporting information is available on the publishers Web site along with the published article.

\section{REFERENCES}

[1] a) Dougherty TJ. Photochemistry in the treatment of cancer. Adv Photochem 1992; 17: 275-311.

b) Dougherty TJ. Photodynamic therapy. Photochem Photobiol 1993; 58: 895-900.

c) Bonnett R. Photosensitizers of the porphyrin and phthalocyanine series for photodynamic therapy. Chem Soc Rev 1995; 24: 19-33.

[2] a) Cadet J, Ravanat J-L, Martinez GR, Medeiros MHG, Di Mascio P. Singlet oxygen oxidation of isolated and cellular DNA: Product formation and mechanistic insights. Photochem Photobiol 2006; 82: $1219-25$

b) Ravanat J-L, Saint-Pierre C, Di Mascio P, Martinez GR, Medeiros MHG, Cadet J. Damage to isolated DNA mediated by singlet oxygen. Helv Chim Acta 2001; 84: 3702-9.

[3] a) Montagnon T, Tofi M, Vassilikogiannakis G. Using singlet oxygen to synthesize polyoxygenated natural products from furans. Acc Chem Res 2008; 41: 1001-11.

b) Lapkin AA, Boddu VM, Aliev GN, Goller B, Polisski S, Kovalev D. Photo-oxidation by singlet oxygen generated on nanoporous silicon in a LED-powered reactor. Chem Eng J 2008; 36: 331-6.

[4] a) Goncalves ES, Ogilby PR. "Inside" vs "Outside" Photooxygenation reactions: Singlet-oxygen mediated surface passivation of polymer films. Langmuir 2008; 24: 9056-65.

b) Pospísil J, Nespurek S, Pilar J. Impact of photosensitized oxidation and singlet oxygen on degradation of stabilized polymers. Polym Degrad Stabil 2008: 93; 1681-8.

c) Tsay JM, Trzoss M, Shi L, et al. Singlet Oxygen production by peptide-coated quantum dot-photosensitizer conjugates. J Am Chem Soc 2007; 129: 6865-71.

[5] a) Foote CS, Wexler S, Ando W, Higgins R. Chemistry of singlet oxygen. IV. Oxygenations with hypochlorite-hydrogen peroxide. J Am Chem Soc 1968; 90: 975-81.

b) Held AM, Halko DJ, Hurst JK. Mechanisms of chlorine oxidation of hydrogen peroxide. J Am Chem Soc 1978; 100: 573240.

c) Khan AU. Quantitative generation of singlet $\left({ }^{1} \Delta_{\mathrm{g}}\right)$ oxygen from acidified aqueous peroxynitrite produced by the reaction of nitric oxide and superoxide anion. J Biolumin Chemilumin 1995; 10: 329-33.

[6] Schmidt R, Schweitzer S. Physical mechanisms of generation and deactivation of singlet oxygen. Chem Rev 2003; 103: 1685.

[7] Alarcón E, Henríquez C, Aspée A, Lissi EA. Chemiluminescence associated with singlet oxygen reactions with amino acids, peptides and proteins. Photochem Photobiol 2007; 83: 475-80.

[8] Hallett FR, Hallett BP, Snipes W. Reactions between singlet oxygen and the constituents of nucleic acids. Biophys J 1970; 10: 30515.

[9] a) Foote CS. Photosensitized oxygenations and the role of singlet oxygen. Acc Chem Res 1968; 1: 104-10. b) Anderson SM, Krinsky NI. Protective action of carotenoid pigments against photodynamic damage to liposomes. Photochem Photobiol 1973; 18: 403-08.

[10] DeRosa MC, Crutchley RJ. Photosensitized singlet oxygen and its applications. J Coord Chem Rev 2002; 233-234: 351-71.

[11] Foote CS. Definition of type I and type II photosensitized oxidation. Photochem Photobiol 1991; 54: 659-64.

[12] Fukuzumi S, Fujita S, Suenobu T, et al. Electron transfer properties of singlet oxygen and promoting effects of scandium ion. J Phys Chem A 2002; 106: 1241-7.

[13] Gouterman M, Schwarz FP, Smith PD, Dolphin D. Porphyrins XXVII. Spin-orbit coupling and luminescence of group IV complexes. J Chem Phys 1973; 59: 676-90.

[14] a) Dabrowski JM, Pereira MM, Arnaut LG, et al. Synthesis, photophysical studies and anticancer activity of a new halogenated water-soluble porphyrin. Photochem Photobiol 2007; 83: 897903.

b) Serra AC, Pineiro M, Rocha Gonsalves AMd'A, et al. Halogen atom effect on photophysical and photodynamic characteristcs of derivatives of 5,10,15,20-tetrakis(3-hydrophenyl)porphyrin. J Photochem Photobiol B 2008; 92: 61-7.

c) Azenha EG, Serra AC, Pineiro M, et al. Heavy-atom effects on metalloporphyrins and polyhalogenated porphyrins. Chem Phys 2002; 280: 177-90.

d) Pineiro M, Pereira MM, Rocha Gonsalves AMd'A, Arnaut LG, Formosinho SF. Singlet oxygen quantum yields from halogenated chlorines: potential new photodynamic therapy agents. J Photochem Photobiol A 2001; 138: 147-57.

[15] Bonnett R, Harriman A, Kozyrev AN. Photophysics of halogenated porphyrins. J Chem Soc Faraday Trans 1992; 88: 763-9.

[16] Seybold PG, Gouterman M. Porphyrins XIII. Fluorescence spectra and quantum yields. J Mol Spectrosc 1969; 31: 1-13.

[17] a) Kim JB, Leonard JJ, Longo FR. A mechanistic study of the synthesis and spectral properties of meso-tetraarylporphyrins. J Am Chem Soc 1972; 94: 3986-92.

b) Gradyushko AT, Kozhich DT, Solov'ev KN, Tsvirko MP. Synthesis and NMR spectra of halo derivatives of tetraphenylporphine. Doklady Akademii Nauk BSSR 1972; 16: 534-7.

[18] Redmond RW, Gamlin JN. A compilation of singlet oxygen yields from biologically relevant molecules. Photochem Photobiol 1999; 70: 391 .

[19] Gouterman M. Spectra of porphyrins. J Mol Spectrosc 1961; 6: 138-63.

[20] Crosby GA, Demas JN. Measurement of photoluminescence quantum yields. Rev J Phys Chem 1971; 75: 991-1024.

[21] a) Yang SI, Seth J, Strachan J-P, et al. Ground and excited state electronic properties of halogenated tetraarylporphyrins. Tuning and building blocks for porphyrin-based photonic devices. J Porphyrins Phthalocyanines 1999; 3: 117-47.

b) Quimby DJ, Longo FR. Luminescence studies on several tetraarylporphins and their zinc derivatives. J Am Chem Soc 1975; 97: 5111-7.

[22] Strickler SJ, Berg RA. Relationship between absorption intensity and fluorescence lifetime of molecules. J Chem Phys 1962; 37: 814-22.

[23] Wilson T. Excited singlet molecular oxygen in photooxidation. J Am Chem Soc 1966; 88: 2898-902.

[24] Ake RL, Gouterman M. Porphyrins XIV. Theory for the luminescent state in VO, Co, Cu complexes. Theor Chim Acta 1969; 15: 20-42.

[25] a) Ghosh A. Substituent effects on valence ionization potentials of free base porphyrins: A local density functional study. J Am Chem Soc 1995; 117: 4691-9.

b) Vangberg T, Ghosh A. Direct porphyrin-aryl orbital overlaps in some meso-Tetraarylporphyrins. J Am Chem Soc 1998; 120: 6227 30 .

[26] Silvers SJ, Tulinsky A. The crystal and molecular structure of triclinic tetraphenylporphyrin. J Am Chem Soc 1967; 89: 33317.

[27] Eaton SS, Eaton GR. Effects of para substituent and metal ion on rates of phenyl ring rotation in ruthenium, indium, and titanium 
complexes of para-substituted tetraphenylporphyrins. J Am Chem Soc 1977; 99: 6594-9.

[28] (a) Strachan JP, Gentemann S, Seth J, et al. Effects of orbital ordering on electronic communication in multiporphyrin arrays. J Am Chem Soc 1997; 119: 11191-201.

(b) Osuka A, Tanabe N, Kawabata S, Yamazaki I, Nishimura Y. Synthesis and intramolecular electron- and energy-transfer reactions of polyyne- or polyene-bridged diporphyrins. J Org Chem 1995; 60: 7177-85.

[29] Kalsbeck WA, Seth J, Bocian DF. Evidence for porphyrin $(\pi)$-chlorine (p) orbital overlap in the $\pi$-cation radicals of zinc(II) and magnesium(II) tetrakis(o-dichlorophenyl)porphyrin. Inorg Chem 1996; 35: 7935-7.

[30] Solov'ev KN, Borisevich EA. Intramolecular heavy-atom effect in the photophysics of organic molecules. Phys Usp 2005; 48: 231-53.
[31] McClure DS. Triplet-singlet transitions in organic molecules. Lifetime measurements of the triplet state. J Chem Phys 1949; 17: 905-13.

[32] Birks JB. Photophysics of Aromatic Molecules," Wiley Interscience, New York, 1970 .

[33] McGlynn SP, Azumi T, Kinoshita M. Molecular Spectroscopy of the Triplet State," Prentice Hall, Englewood Cliffs, 1969.

[34] a) Mang TS, Allison R, Hewson G, Snider W, Moskowitz R. A phase II/III clinical study of tin ethyl etiopurpurin (Purlytin)induced photodynamic therapy for the treatment of recurrent cutaneous metastatic breast cancer. Cancer J Sci Am 1998; 4: 378-84. b) Gorman A, Killoran J, O'Shea C, Kenna T, Gallagher WM, O'Shea DF. In vitro demonstration of the heavy-atom effect for photodynamic therapy. J Am Chem Soc 2004; 126: 10619-31.

[35] Vangberg T, Ghosh A. Direct porphyrin-aryl orbital overlaps in some meso-tetraarylporphyrins. J Am Chem Soc 1998; 120: 6227-30.

(C) Nifiatis et al.; Licensee Bentham Open.

This is an open access article licensed under the terms of the Creative Commons Attribution Non-Commercial License (http://creativecommons.org/licenses/ by-nc/3.0/) which permits unrestricted, non-commercial use, distribution and reproduction in any medium, provided the work is properly cited. 